\title{
Preliminary Assessment of Total Mercury Content in Sri Lankan Seer Fish Scomberomorus commerson
}

\author{
Alwishewa R.A. and Attygalle M.V.E. \\ Department of Zoology, Faculty of Applied Sciences, University of Sri Jayewardenepura, \\ Gangodawila, Sri Lanka \\ ralwishewa@gmail.com
}

\begin{abstract}
Fish is an important source of food providing valuable nutrients and many health benefits. Unfortunately, consumption of fish contaminated with mercury can expose humans to mercury poisoning. Mercury is a heavy metal pollutant that once released into the environment mostly affects aquatic ecosystems as it bioaccumulates and biomagnifies up the food chain in large fish in higher trophic levels thereby causing serious health concerns for consumers. Total mercury levels in the muscle tissue have been determined in some Sri Lankan marine fish of large size such as tuna, shark and sword fish.
\end{abstract}

This study is a preliminary assessment of total mercury content (TMC) in different tissues of Sri Lankan Seer fish Scomberomorus commerson. The TMC was determined separately in skin, red muscle, and white muscle. Samples were prepared by wet digestion method and analysed using Atomic Absorption Spectrophotometric technique. Monthly Sampling was carried out in the year 2012 from March-November. Overall eight fresh specimens of consistent length $(70-80 \mathrm{~cm})$ and weight class $(2.25-2.50 \mathrm{~kg})$ were purchased at random sellers from the central fish market complex of the Ministry of Fisheries and Aquatic Resources Development, Peliyagoda.

All total mercury levels were below the international standard of $0.5 \mu \mathrm{g} \mathrm{g}^{-1}$ (US FDA). Significant variances were observed among the different tissue parts tested $(p<0.05)$. Mean TMC varied in decreasing order as, white muscle > red muscle > skin. Even though skin is commonly assumed to contain higher levels of mercury, results from skin were the lowest recorded in the study. The results reveal that mercury binding is tissue-specific and accumulates differently in different tissue types. It has been reported that mercury builds up in the muscle tissue and cannot be removed by removing the skin and trimming away fatty areas of the fish.

The estimated weekly intake (EWI) of mercury by average consumers in Sri Lanka was calculated as $0.0306 \mu \mathrm{g} \mathrm{kg}^{-1}$ for $S$. commerson based on the average adult (50 kg) consuming $16.57 \mathrm{~g} \mathrm{day}^{-1}$ of fish. This is below the provisional tolerable weekly intake of $5 \mu \mathrm{g} \mathrm{kg}^{-1}$ body weight established for total mercury (WHO).

Total mercury levels are dependent on age and consequently length of fish. From this preliminary study one can conclude that Sri Lankan Seer fish Scomberomorus commerson below the $80.0 \mathrm{~cm}$ total length is safe from undue contamination of mercury. However further extensive sampling is necessary to establish this conclusion.

Keywords: Scomberomorus commerson, Total mercury 